\title{
Cognitive load theory in simulations to facilitate critical thinking in radiography students
}

\author{
A Louw, BRad, BRad Hons, MTech Rad, DTech Rad \\ Department of Medical Imaging and Radiation Sciences, Faculty of Health Sciences, University of Johannesburg, South Africa (at the time of the research reported in \\ this article)
}

Corresponding author: A Louw (rooirokkie.al@gmail.com)

\begin{abstract}
Background. Problem solving and critical thinking are top future skills. High-fidelity simulations improve critical thinking, but also increase students' cognitive load, possibly limiting their learning. Educators should therefore consider learning outcomes, problems that require critical thinking, the relationship between working and long-term memory, and intrinsic and extraneous cognitive loads when developing simulation scenarios.

Objective. To report on the application of cognitive load theory (CLT) and students' responses in terms of problem solving and new insights during and after a simulation experience.

Methods. A high-fidelity simulation, targeting multilevel communication, teamwork and prioritisation of learning outcomes, was designed according to CLT. Eighty students participated in presimulation knowledge, skills and attitudes acquisition and 10 participated in the simulation. A qualitative descriptive design was followed and data were collected through video/audio recordings of the simulation and reflection session, supported by educator and critical observer notes. Qualitative content analysis allowed comprehensive summarisation of students' problem-solving abilities and emerging new insights.

Results. Eighty second-year radiography students formed the target population, with 10 simulation participants comprising the sample. Communication with health professionals was good, but lacking towards patients. Intraprofessional team collaboration was suboptimal, but interprofessional team collaboration was good. Students were mostly unfamiliar with the prioritisation responsibility. Upon reflection, students came to new insights regarding teamwork and prioritisation.

Conclusion. After application of CLT, critical thinking to facilitate problem solving during simulation was suggested and post-simulation reflection facilitated new insights. The exposure of large groups to the benefits of simulation validates further investigation.
\end{abstract}

Afr J Health Professions Educ 2021;13(1):41-46. https://doi.org/10.7196/AJHPE.2021.v13i1.1313

The World Economic Forum identified complex problem solving, critical thinking skills that facilitate it and creativity as the top skills needed in 2020 and beyond. ${ }^{[1]}$ Critical thinking broadly consists of three components, i.e. information, processing (thinking) skills and the habit of using the processed information to direct behaviour. ${ }^{[2]}$ In the health professions, the ability to gather information and evaluate associated assumptions and evidence to guide courses of action are key to preventing and solving problems. ${ }^{[3]}$ Numerous studies reported that high-fidelity simulations are useful to improve critical thinking, decision-making, confidence, all-round communication skills and readiness for practice, ${ }^{[4-6]}$ and in medical and nursing education, it is extensively used to link classroom teaching to clinical practice. ${ }^{[7-10]}$

The essence of simulation-based education in healthcare is to expose students to real-life situations without the risk of harming patients, while they pursue specific learning outcomes. ${ }^{[11,12]}$ The innate authentic nature of highfidelity simulations can however profoundly increase students' cognitive load, which may affect their learning experience and clinical performance. The incorporation of cognitive load theory (CLT) to facilitate the development of simulations that consider the cognitive interplay between working memory and long-term memory to optimise learning, ${ }^{[13]}$ is therefore indicated. CLT is based on the principle that a person's working memory - the part concerned with learning and problem solving - has a limited capacity when dealing with novel information. However, when the working memory can access appropriate information stored in the long-term memory, its capacity seems to be limitless. ${ }^{[14]}$ Students' total working memory load or cognitive load consists of the sum of the intrinsic cognitive load and the extraneous cognitive load. Intrinsic load (IL) refers to the inherent difficulty of the information or simulation, while extraneous load (EL) mostly refers to suboptimal instructional design factors that do not enhance learning. ${ }^{[15]}$ Should either one or both components exceed working memory capacity, learning will be impaired. In developing simulation scenarios, educators should therefore consider the inherent difficulty of the scenario and increase students' working memory capacity accordingly by way of populating their long-term memories with the necessary information prior to the simulation. ${ }^{[15]}$ Several interacting scenario elements that need to be considered simultaneously during the simulation, should preferably not be based on skills not yet mastered, ${ }^{[15]}$ and a simulation requiring e.g. clinical reasoning, decision-making and complex communication, should be written around radiographic procedures that students can competently perform without much thinking. It is, however, also true that a slightly excessive cognitive load often results in associated increased learning, ${ }^{[14]}$ and educators' challenge is to find the balance between an increased cognitive load that stimulates and motivates students and one that impairs learning. ${ }^{[15]}$

This article reports students' responses in terms of problem solving and new insights following the incorporation of CLT into a high-fidelity simulation specifically designed to facilitate critical thinking. Prepopulation 
of students' long-term memory banks and their working memories' problem-solving abilities during the simulation are described, insights that emerged during post-simulation reflection are discussed and shortcomings and future research needs are identified. The simulation scenario itself and timing of the different interplaying elements are detailed elsewhere. ${ }^{[4]}$

\section{Methods}

A qualitative descriptive design ${ }^{[16,17]}$ was used and data were collected by means of two video/audio recordings of the simulation and reflection session, supported by four critical observers' notes and the educator's observation notes. Data were analysed through qualitative content analysis. ${ }^{[16]}$ Whereas multiple sources verify the data, and descriptive and interpretive validity is enhanced by the nature of the qualitative descriptive study design, ${ }^{[18]}$ the researcher's educational involvement and lens are acknowledged to be considered by the reader.

\section{Context}

The simulation was conducted in an on-campus high-fidelity simulation laboratory and involved 80 radiography students in the first month of their second year. As part of their educational programme, all 80 students were actively involved in the presimulation scaffolding of knowledge, skills and attitudes, and all received information regarding the research study and what participation would entail. All were told they could withdraw from the study at any time and that non-participation would not disadvantage them. Ten students volunteered and signed informed consent to participate in the simulation and be video/audio recorded. Students were assured that all recorded material would be kept safe and confidential as research data.

\section{Preparation}

An interprofessional, stress-loaded, multicase simulation scenario was designed to target specific learning outcomes, i.e. multilevel communication, teamwork and prioritisation. Students did not receive explicit lectures on the outcomes - these were at best only implied through the hidden curriculum of various modules. As these higher cognitive skills incorporated various interacting elements and involved some problem solving, it constituted a high IL that required thorough preparation of students' long-term memory banks with basic knowledge, skills and attitudes. This would expand students' working memory capacity to allow optimal consideration of all the interacting elements and problem solving required during the simulation Table 1 shows the preparation process that was scaffolded over 3 weeks. Offering strategy and content considered the limited capacity of the working memory to deal with new information, and both started with the simplest information, escalating in complexity over time. ${ }^{[13,14]}$

Small-group discussions are powerful social learning platforms and groups consisted of 5 students who each received clinical training in different settings, resulting in discussions that represented rich conglomerations of clinical experience, underpinned by the academic content addressed during the previous weeks. Considering the broad definition of critical thinking, which contains the components of information, thinking about (discussing) the information, and allowing the thinking (discussing) to direct decisions and actions, ${ }^{[2]}$ students were well prepared for the simulation once they progressed through the scaffolding steps.

\section{Simulation}

Five days prior to the simulation, the 10 volunteering students were briefed. Table 2 shows how prebriefing minimised their EL, which would not contribute to learning. Table 2 also indicates the different roles that the students fulfilled. Detail about the simulation scenario and the tasks to be performed was unknown to the participants until the simulation started.

Primary simulation tasks entailed chest and elbow imaging, but learning outcomes involved secondary tasks, such as multilevel communication, teamwork and prioritisation. Anchoring the scenario on first-year projections considered two CLT facts: (i) working memory capacity is limited unless it can draw knowledge and skills from long-term memory; ${ }^{[14]}$ and (ii) primary and secondary tasks use working memory as a cognitive resource. Resources for secondary tasks therefore depend on resources remaining once primary tasks are completed. ${ }^{[19]}$ As preparation, prebriefing and choice of primary tasks aimed to avail most of the students' working memory capacity for secondary tasks, the simulation IL was increased to mimic a realistic situation in the casualty department of a small hospital in South Africa (SA). A range of events presented the 3 student radiographers with several interacting elements and an array of problems that required critical thinking. Table 3 shows the elements that increased IL, problems that emerged throughout the simulation and critical thinking components that were needed to address each. The emotional impact of the simulation on individuals and students' personal coping strategies is not included.

Table 1. Cognitive load theory and presimulation preparation of 80 students' long-term memory banks

\begin{tabular}{lll}
\hline $\begin{array}{l}\text { Scaffolding steps before } \\
\text { simulation, weeks }\end{array}$ & Learning mode & Offering strategy \\
\hline 4 & Synchronous & Classroom discussions \\
3 & Asynchronous & $\begin{array}{l}\text { Readings, videos, } \\
\text { website links posted } \\
\text { onto university's learning } \\
\text { management system } \\
\end{array}$ \\
& Social & $\begin{array}{l}\text { Small-group discussions } \\
\text { of worksheets posted onto } \\
\text { learning management } \\
\text { system }\end{array}$ \\
& &
\end{tabular}

Content

Chest and elbow imaging

NAT in paediatric patients Additional trauma chest, elbow and NAT image appearance information and procedural guidelines when sensing possible NAT cases Trauma chest, elbow and NAT images with probing questions

\section{Purpose}

Revision of first-year syllabus Introduction of new content Preparing students for confident and knowledgeable participation in forthcoming small-group discussions

To clearly indicate to students their learning goal, provide an opportunity to relate their existing knowledge to new information, focus their attention on important aspects and stimulate critical thinking through challenging questions 


\begin{tabular}{|c|c|c|}
\hline Factors increasing extraneous load & Strategy to minimise extraneous load & Effect \\
\hline \multirow[t]{4}{*}{ Stress and anxiety during simulation } & $\begin{array}{l}\text { Students invited to familiarise themselves with the fictitious } \\
\text { scenario setting, available equipment and accessories in the } \\
\text { simulation laboratory }\end{array}$ & $\begin{array}{l}\text { Students were prepared in terms of venue layout, } \\
\text { capabilities and limitations of equipment and } \\
\text { accessories }\end{array}$ \\
\hline & $\begin{array}{l}\text { Students informed of } 10 \text { roles to be filled: } 3 \text { student } \\
\text { radiographers, } 2 \text { nurses, } 1 \text { patient family member and } \\
4 \text { critical observers } \\
\text { They decided who would take up which roles }\end{array}$ & $\begin{array}{l}\text { Students could imagine possible role nuances, and } \\
\text { a sense of self-determination was introduced }\end{array}$ \\
\hline & $\begin{array}{l}\text { Students informed of time frames of different components: } \\
\text { simulation, image interpretation and reflection }\end{array}$ & $\begin{array}{l}\text { Students knew in advance what their participation } \\
\text { would entail }\end{array}$ \\
\hline & Students received aim and objectives of simulation & $\begin{array}{l}\text { Students could anticipate possible challenges } \\
\text { incorporated into the scenario }\end{array}$ \\
\hline
\end{tabular}

\section{Ethical approval}

The educational study obtained ethical clearance from the Research Ethics Committee of Faculty of Health Sciences of the host university (ref. no. REC-01-71-2016), where the researcher was a radiography educator who used simulation to achieve active student involvement that embraces thinking about, understanding of, and thus learning of curricular content.

\section{Results and discussion}

Results are presented and discussed in the acceptable qualitative tradition, alongside literature references and participant quotations.

\section{Critical thinking and problem solving during simulation}

The 10 radiography student participants represented 3 cultural groups and 6 clinical training centres. There were 2 males and 8 females - all were $>18$ years old. There were 2 role-play nurses, 1 played the baby's family member, 4 served as critical observers and 3 remained student radiographers. Qualitative content analysis of the simulation video/audio recording, supported by the educator's observation notes, focused on a close and low inference description of the content. ${ }^{[16]}$ Primary simulation tasks, i.e. low IL chest and elbow imaging, were performed well. Performance of secondary tasks and progression towards the learning outcomes are described in the following paragraphs.

Critical thinking occurs when students are motivated and challenged to engage in higher-level thought processes. ${ }^{[20]}$ The simulation was therefore developed to spark students' interest and enthusiasm by incorporating high IL secondary tasks, presenting multilevel communication, teamwork and prioritisation problems as challenging elements. Competent clinical reasoning, decision-making and reflective problem solving are subcomponents of critical thinking, ${ }^{[21,22]}$ and where problems were adequately solved, it is accepted that students engaged in critical thinking.

\section{Multilevel communication}

Communication challenges required students to adapt their communication styles between patients, a family member, nurses and a doctor. They found the non-routine task of communicating their image observations to the doctor challenging but necessary, owing to the radiologist's absence. Students' knowledge regarding chest and non-accidental trauma image appearances and complications equipped them to communicate the adult's tension pneumothorax and the baby's fractures with its implications accurately, resulting in prompt, appropriate management. Communication with nurses and the family member was professional, but minimal with 'patients'. As the patients were manikins, it could have contributed to this shortcoming; alternatively, students may have over-focused on other scenario elements.

\section{Teamwork}

Intraprofessional team collaboration (among student radiographers) was not optimal. Students seemed unsure of who-should-do-what and much time was initially wasted by incoherent actions. However, once the second patient's imaging started, workflow improved. The simulation introduced students to the concept of interprofessional team collaboration (among all staff) to mutually pursue optimal patient care. While they seemed to have fitted into this expanded dimension relatively well, the reflection session revealed that much learning took place in this regard.

\section{Prioritisation}

Students found prioritisation of patients and imaging requests the biggest challenge. They ignored several requests for the baby's chest imaging while they were busy with the adult's elbow and only responded after a final urgent call from the nurses, indicating immediate need of radiographs. On the positive side, students did consider the benefits and risks of imaging the pregnant adult (and fetus) and promptly proceeded with chest imaging.

Regarding all these targeted learning outcomes, students applied their existing knowledge, skills and attitudes, made decisions and acted accordingly. All three components of critical thinking were thus used to address the various problems that arose, even though not all actions were optimal at all times.

\section{Post-simulation reflection and critical thinking}

Reflection (debriefing) immediately after a simulation is considered the most important component of a simulation, as it consolidates learning that (often subconsciously) took place during the simulation. ${ }^{[23]}$ It allows students to develop new insights that direct their future performance as a result of learning through experiencing. ${ }^{[24]}$ It is a vital cognitive step in the critical thinking process, as the identification and evaluation of what did/did not work are essential to improve knowledge and problemsolving skills. ${ }^{[27]}$

To limit unintended bias resulting from the educator's expectations and to ascertain whether students can come to new insights by themselves, post-simulation reflection was led by the 4 critical observers, and formative educator input was minimal. To assist them, observers were each given an 


\begin{tabular}{|c|c|c|}
\hline Elements that increased intrinsic load & Emerging problems & Critical thinking components \\
\hline $\begin{array}{l}\text { Scenario staged on Sunday morning, } \\
03 \mathrm{~h} 00\end{array}$ & $\begin{array}{l}\text { Limited staff, qualified radiographer } \\
\text { elsewhere } \\
\text { Students expected to function } \\
\text { autonomously regarding full range of } \\
\text { imaging responsibilities }\end{array}$ & $\begin{array}{l}\text { Embedded knowledge, skills, attitudes } \\
\text { Thinking about it in current context } \\
\text { Making appropriate decisions }\end{array}$ \\
\hline No radiologist & $\begin{array}{l}\text { Students expected to comment on X-ray } \\
\text { images }\end{array}$ & $\begin{array}{l}\text { Embedded image evaluation and interpretation knowledge } \\
\text { and skills } \\
\text { Applying it to displayed images } \\
\text { Making appropriate judgements about commenting to doctor }\end{array}$ \\
\hline $\begin{array}{l}\text { Setting: casualty department with } \\
1 \text { mobile X-ray unit }\end{array}$ & $\begin{array}{l}\text { Routine projections may need } \\
\text { adaptations according to patients' } \\
\text { conditions }\end{array}$ & $\begin{array}{l}\text { Embedded knowledge, skills, attitudes } \\
\text { Applying it to current context } \\
\text { Adjusting routine procedures to ensure optimal care }\end{array}$ \\
\hline 2 patients needing simultaneous imaging & $\begin{array}{l}\text { Students to consider urgency of adults' } \\
\text { chest and elbow v. baby's chest }\end{array}$ & $\begin{array}{l}\text { Embedded knowledge, attitudes } \\
\text { Applying it to current patients' clinical history and conditions } \\
\text { Prioritising to promote optimal care }\end{array}$ \\
\hline $\begin{array}{l}\text { 1st patient: adult, } 38 \text { weeks' pregnant, } \\
\text { involved in high-impact motor vehicle } \\
\text { accident (chest and elbow) }\end{array}$ & $\begin{array}{l}\text { Students to consider benefits and risks } \\
\text { of irradiating pregnant patient and fetus }\end{array}$ & $\begin{array}{l}\text { Embedded knowledge, skills, attitudes } \\
\text { Relating it to clinical condition of adult and fetal development } \\
\text { plus benefits and risks to both - in case of imaging and non- } \\
\text { imaging } \\
\text { Applying techniques to limit fetal radiation } \\
\text { Making appropriate decisions to promote optimal adult } \\
\text { and fetal care }\end{array}$ \\
\hline $\begin{array}{l}\text { Adult's chest image indicates tension } \\
\text { pneumothorax }\end{array}$ & $\begin{array}{l}\text { Potentially fatal, needs immediate } \\
\text { management }\end{array}$ & $\begin{array}{l}\text { Embedded knowledge regarding recognition and implications } \\
\text { of tension pneumothorax } \\
\text { Applying it to current context, realising doctor is occupied } \\
\text { but needs to be informed urgently } \\
\text { Communicating imaging outcome appropriately to facilitate } \\
\text { optimal care }\end{array}$ \\
\hline 2nd patient: 18 -month-old baby (chest) & $\begin{array}{l}\text { Baby's condition serious and } \\
\text { deteriorating, causing stress to all staff } \\
\text { Students to continuously act } \\
\text { professionally }\end{array}$ & $\begin{array}{l}\text { Embedded knowledge, skills, attitudes } \\
\text { Applying it to current situation } \\
\text { Making conscious decisions: demonstrating confidence, } \\
\text { competence and control }\end{array}$ \\
\hline $\begin{array}{l}\text { Baby's chest image indicates several rib } \\
\text { and clavicle fractures in various healing } \\
\text { stages } \\
\text { Previous lower-extremity images } \\
\text { indicate metaphyseal fractures }\end{array}$ & $\begin{array}{l}\text { Injury combination highly suggestive } \\
\text { of NAT } \\
\text { Students expected to realise implications }\end{array}$ & $\begin{array}{l}\text { Embedded knowledge regarding recognition of injuries } \\
\text { and possible implication of injury combination } \\
\text { Applying it to current context, realising doctor may not } \\
\text { immediately realise implications } \\
\text { Communicating observation and possible implications } \\
\text { appropriately to facilitate optimal care }\end{array}$ \\
\hline $\begin{array}{l}\text { Baby's family member disrupts } \\
\text { imaging, challenging students' patience, } \\
\text { communication skills and general } \\
\text { professional demeanour }\end{array}$ & $\begin{array}{l}\text { Students to continuously act } \\
\text { professionally }\end{array}$ & $\begin{array}{l}\text { Embedded skills, attitudes } \\
\text { Applying it to current situation, realising possible legal } \\
\text { implications of suspected NAT case } \\
\text { Acting appropriately and communicating professionally }\end{array}$ \\
\hline $\begin{array}{l}\text { Both 'patients' were high-fidelity } \\
\text { manikins, producing realistic verbal } \\
\text { sounds: adult moaning and baby crying }\end{array}$ & $\begin{array}{l}\text { 'Patient' distress sounds can cause stress } \\
\text { in students } \\
\text { Students to continuously act } \\
\text { professionally }\end{array}$ & $\begin{array}{l}\text { Embedded skills, attitudes } \\
\text { Applying it to current situation } \\
\text { Acting professionally }\end{array}$ \\
\hline $\begin{array}{l}\text { Real-life, casualty unit, additional } \\
\text { 'patients', heart-rate monitors, } \\
\text { ringing telephones and verbal staff } \\
\text { communications }\end{array}$ & $\begin{array}{l}\text { Authentic clinical environment and } \\
\text { realistic distracting elements challenged } \\
\text { students' professionalism }\end{array}$ & $\begin{array}{l}\text { Embedded skills, attitudes } \\
\text { Applying it to current situation } \\
\text { Acting professionally: displaying general team coherence } \\
\text { aimed at optimal patient management and care }\end{array}$ \\
\hline
\end{tabular}

NAT $=$ non-accidental trauma.

observation guide, as well as the simulation aim and objectives to focus their observations during the simulation and to guide the reflective discussion. The 10 radiography students contributed to the reflection from their personal radiography contexts. Findings are based on content analysis of a video/audio recording of the reflection session, supported by the critical observers' notes. 
Observers initiated the discussion by highlighting positives and negatives regarding basic radiographic skills, after which they addressed higherorder skills required during the simulation. Group cohesion seemed strong, students appeared to feel safe to reflect honestly and did not try to defend their less ideal decisions, but rather explained their thoughts. As they were from different clinical settings, a variety of perspectives emerged, resulting in widening everyone's outlook on how to recognise sub-optimal decisions and adjust future approaches appropriately. The simulation was designed to challenge students in terms of communication, teamwork and prioritisation, and most of the dialogue fitted into these targeted learning outcome categories, with evidence of a fourth category, i.e. situational and mental preparedness.

\section{Communication}

The imaging team spontaneously admitted their lack of patient communication and ascribed it to the intenseness of the scenario. This suggests that their working memories were slightly under-capacitated to cope with all the scenario elements:

'... you just think, you don't explain to the patient ... ${ }^{[4]}$

\section{Teamwork}

The group realised the need for imaging team members to decide beforehand on who-should-do-what, to prevent haphazardness:

'I was confused ... I did not know what to do first, if it will be ok.'

The two who role-played nurses provided additional nursing perspectives towards the inter-professional team collaboration concept:

'This scenario made me appreciate other people's professions ... the nurses have a lot on their shoulders ...?[4]

It was also realised that optimal patient care requires different teams to assist each other:

'Next time ... when the doctor is busy with the patient, I will think to give her the lead apron to carry on with her work - this is something I was never thinking of before. ${ }^{[4]}$

\section{Prioritisation}

Students admitted that the situation that prompted them to interrupt the adult's elbow imaging in favour of the baby's chest, was new to them:

'I was not sure if we could, if we could not, as I have never been in that situation before. ${ }^{[4]}$

Prioritisation with its implied responsibility was much discussed, and students started realising the importance of thinking about multiple simultaneous imaging requests and the role of imaging in the immediate management of different patient conditions:

'... now I know the importance of decision-making ... I will think about a decision ... what should be done first.'[4]

\section{Situational and mental preparedness}

An additional learning outcome echoed by the whole group, was that of situational and mental preparedness:

'These things happen for real. If you are not used to such scenarios, you always gonna be chilled ... The reality is we need patients like this to prepare you mentally.[4]
Teaching strategies that allow students to think about learning content are vital to understanding it, and active engagement with learning content instead of passive listening to a lecture, cultivates critical thinking. ${ }^{[25,26]}$ The emergence of the untargeted learning outcome, as well as discussions around the three targeted outcomes, indicated the presence of the three basic critical thinking components during the reflection session. All students had knowledge of the simulation happenings, thought about it, discussed it in relation to their prior knowledge and expertise, and came to new insights that will affect their future behaviour in similar situations:

'Like now, we kind of learnt what to do. We've seen what - like - most people [in the team] think about it. ${ }^{\text {[4] }}$

\section{Conclusion}

CLT was applied in the preparation and execution of a high-fidelity simulation that aimed to achieve the learning outcomes of multilevel communication, teamwork and prioritisation. Several problems related to these outcomes were embedded in the scenario and required critical thinking for solving strategies. Students' decisions were not optimal in all cases, but problems were mostly managed well, suggesting largely adequate cognitive resources and application of three basic critical thinking components. Post-simulation reflection allowed students to communicate with each other in seeking and finding solution $\mathrm{s}^{[27]}$ and indicated that students can come to new insights by themselves, without formal instruction. As simulation provides a platform where students can learn from their mistakes without harming patients, ${ }^{[11,12]}$ the simulation was considered successful, as it exposed students to problem solving through critical thinking and sensitised students and educator to professional practice components in need of attention.

Study findings are not optimal, as students' problem-solving abilities were not summatively assessed and formative judgement was based solely on the educator's long-standing expertise in the radiography domain. There was also no attempt to measure students' cognitive loads, as knowledge on the precise gauging of IL and EL is lacking. ${ }^{[28]}$ The major shortcoming of the simulation, however, was the inclusion of only 10 of 80 students. To provide equitable education to all, further research into simulation strategies to hone the critical thinking skills of large groups within the constraints of curricula, timetables and available venues, is indicated.

\section{Declaration. None.}

Acknowledgements. The author acknowledges all the students and simulation laboratory staff of the Faculty of Health Sciences, University of Johannesburg, who participated in this simulation experience in 2017.

Author contributions. AL conceptualised and executed the study and wrote the article.

Funding. None.

Conflicts of interest. None.

1. Gray A. The 10 skills you need to thrive in the fourth industrial revolution. World Economic Forum: Agenda. 2016 https://www.weforum.org/agenda/2016/01/the-10-skills-you-need-to-thrive-in-the-fourth-industrial-revolution/ (accessed 13 January 2020).

2. Foundation for Critical Thinking. Critical thinking as defined by the National Council for Excellence in Critica Thinking. 1987. http://www criticalthinking org/pages/defining-critical-thinking/766 (accessed 13 January 2020). 3. Alfaro-LeFevre R. Critical Thinking, Clinical Reasoning, and Clinical Judgement: A Practical Approach. 6th ed. Philadelphia: Elsevier, 2017:3

4. Louw A. High fidelity simulation based training in radiography. In: Horsted A, ed. New Innovations in Teaching and Learning in Higher Education. Faringdon: Libri, 2017:263-287.

5. Hayden JK, Smiley RA, Alexander M, Kardong-Edgren S, Jeffries PR. The NCSBN national simulation study: A longitudinal, randomized controlled study replacing clinical hours with simulation in pre-licensure nursing education. J Nurs Regulat 2014;2(5):S3-S40. https://doi.org/10.1016/\$2155-8256(15)30062-4 
6. Moyer S. Large group simulation: Using combined teaching strategies to connect classroom and clinical learning. Teach Learn Nurse 2016;11(2):67-73. https://doi.org/10.1016/j.teln.2016.01.002

7. Ericsson KA. Deliberate practice and the acquisition and maintenance of expert performance in medicine and related domains. Acad Med 2004;79(10):S70-S81. https://doi.org/10.1097/00001888-200410001-00022

8. Rosen KR. The history of medical simulation. J Crit Care 2008;23(2):157-166. https://doi.org/10.1016/j. jcrc.2007.12.004

9. Buckley $\mathrm{T}$, Gordon $\mathrm{C}$. The effectiveness of high fidelity simulation on medical-surgical registered nurses' ability to recognise and respond to clinical emergencies. Nurse Educ Today 2011;31(7):716-721. https://doi.org/10.1016/ f. nedt.2010.04.004

10. Friederichs H, Weissenstein A, Ligges S, Moller D, Becker JC, Marschall B. Combining simulated patients and simulators: Pilot study of hybrid simulation in teaching cardiac auscultation. Adv Physiol Educ 2014;38(4)343-347. simulators: Pilot study of hybrid simulation

11. Bradley P. The history of simulation in medical education and possible future directions. Med Educ 2006;40(3):254-262 https://doi.org/10.1111/j.1365-2929.2006.02394.x

12. Alinier G, Harwood C, Harwood P, Monatgue S, Ruparelia K. Immersive clinical simulation in undergraduate health care professional education: Knowledge and perceptions. Clin Simul Nurs 2014;10(4):e205-e216. https:// doi.org/10.1016/j.ecns.2013.12.006

13. Bong CL, Fraser K, Oriot D. Cognitive load and stress in simulation. In: Grant VJ, Cheng A, eds. Comprehensive Healthcare Simulation: Paediatrics. Switzerland: Springer International Publishing, 2016:3-17.

14. Van Merriënboer JJG, Sweller J. Cognitive load theory in health professional education: Design principles and strategies. Med Educ 2010;44(1):85-93. https://doi.org/10.1111/j.1365-2923.2009.03498.x

15. Fraser KL, Ayers P, Sweller I. Cognitive load theory for the design of medical simulations. Simul Healthcare 2015;10(5):295-307. https://doi,org/10.1097/SIH.0000000000000097

16. Sandelowski M. Focus on research methods. Whatever happened to qualitative description? Res Nurs Health 2000;23:334-340. https:// doi.org/10.1002/1098-240X(200008)23:4\%3C334::AID-NUR9\%3E3.0.CO;2-C

17. Neergaard MA, Olesen F, Andersen RS, Sondergaard J. Qualitative description - the poor cousin of qualitative research? BMC Med Res Methodol 2009;9(52). https://doi.org/10.1186/1471-2288-9-52
18. Maxwell JA. Understanding and validity in qualitative research. Harvard Educ Rev1992;62(3):279-300.

19. Brünken R, Steinbacher S, Plass JL, Leutner D. Assessment of cognitive load in multimedia learning using dualtask methodology. Experiment Psychol 2002;49(2):109-119. https://doi.org/10.1027//1618-3169.49.2.109

20. Roberts TG, Dyer JE. The relationship of self-efficacy, motivation, and critical thinking disposition to achievemen and attitudes when an illustrated web lecture is used in an online learning environment. J Agric Educ 2005;46(2):12-23. https://doi.org/10.5032/jae.2005.02012

21. Jackson M, Ignavaticius DD, Case B. Conversations in Critical Thinking and Clinical Judgement. Sudbury, MA Jones \& Bartlett, 2006.

22. Facione NC, Facione PA. Critical Thinking and Clinical Reasoning in the Health Sciences: An International Multidisciplinary Teaching Anthology. Millbrae, CA: California Academic Press, 2008

23. Konia M, Yao A. Simulation - a new educational paradigm? J Biomed Res 2013;27(2):75-80. https://doi.org/10.7555/ JBR.27.20120107

24. Kolb DA. Experiential Learning: Experience as the Source of Learning and Development. 2nd ed. New Jersey: Pearson Education, 2015.

25. Paul R. The state of critical thinking today. 2004. http://www.criticalthinking.org/pages/the-state-of-criticalthinking-today/523 (accessed 13 January 2020).

26. Tsui LL. Fostering critical thinking through effective pedagogy: Evidence from four institutional case studies. J High Educ 2002;73(6):740-763. https://doi.org/10.1353/jhe.2002.0056

27. Harasym PH, Tsai T, Hemmati P. Current trends in developing medical students' critical thinking abilities. Kaohsiung J Med Sci 2008;24(7):341-355. https://doi.org/10.1016/S1607-551X(08)70131-1

28. Leppink J. Cognitive load theory: Practical implications and an important challenge. J Taibah Univ Med Sci 2017;12(5):385-391. https://doi.org/10.1016/.j.tumed.2017.05.003

Accepted 1 April 2020. 